\title{
Short-term changes in the anterior segment and retina after small incision lenticule extraction
}

\author{
Yanwei Chen, Huaping Liao, Yue Sun and Xi Shen *
}

\begin{abstract}
Background: To analyse short-term changes in the anterior segment and retina after small incision lenticule extraction (SMILE).

Methods: Patients with myopia scheduled for SMILE were recruited from Ruijin Hospital, Shanghai, China. Basic patient information such as age, sex, and refractive errors was recorded. Ocular measurements were taken before surgery, and 1 day and 1 week after surgery; they included axial length (AL), central corneal thickness (CCT), anterior chamber depth (ACD), lens thickness (LT), white to white (WTW), pupil diameter (PD), macular thickness (MT), ganglion cell layer thickness (GCL), retinal nerve fiber layer thickness (RNFL), choroidal thickness (CT), macular vessel density, and optic disc vessel density.

Results: Sixty-one eyes of 31 patients were selected for this study. AL, CCT, ACD, and postoperative PD were significantly reduced $(p<0.05)$, while LT was thickened after surgery $(p<0.05)$. MT at the fovea decreased 1 day and 1 week after surgery $(p<0.05)$. GCL showed no significant changes after surgery. RNFL was unchanged 1 day after surgery, but the inferior sector was thickened 1 week after surgery. $\subset$ was thicker at the fovea 1 day after surgery and $1.0 \mathrm{~mm}$ from the fovea in the nasal sector 1 week after surgery. Macular vessel density was significantly decreased 1 day after surgery and most recovered in 1 week. Optic disc vessel density decreased at the peripapillary part 1 day after surgery and recovered after 1 week. $\Delta$ ACD and $\Delta \mathrm{LT}$ showed no significant correlation 1 day after surgery. $\Delta \mathrm{ACD}$ was negatively correlated with $\boldsymbol{\Delta L T}$ and sphere 1 week after surgery $(r=-0.847, p<0.000 ; r=-0.398, p=0.002)$. $\Delta \mathrm{LT}$ was positively correlated with the sphere 1 week after surgery $(r=$ $0.256, p=0.048)$.
\end{abstract}

Conclusion: The anterior segment was the most affected, while the retina also underwent changes with regard to MT, RNFL, CT, macular vessel density, and peripapillary vessel density.

Keywords: Small incision lenticule extraction, Anterior segment, Retina, Optical coherence tomography angiography (OCTA)

\section{Background}

Laser refractive surgery has been developing for more than 30 years since Dr. Steven Trokel and his colleagues first reported photorefractive keratectomy (PRK) in 1983 [1]. Subsequently, laser in situ keratomileusis (LASIK), and laser subepithelial keratomileusis (LASEK) developed.

\footnotetext{
*Correspondence: carl_shen2005@126.com

Department of Ophthalmology, Ruijin Hospital Affiliated Shanghai Jiao Tong University, School of Medicine, Shanghai, China
}

About 10 years ago, small-incision lenticule extraction (SMILE) gradually came up and now has become the most popular surgery for refraction correction for its effectiveness, stability, and safety $[2,3]$.

As myopia patients grow, the effects of refractive surgeries also attract doctors' concerns. LASIK and SMILE are so similar that researchers have compared them in different ways. Changes in LASIK have been studied extensively. Cornea biomechanics decrease after both

(c) The Author(s). 2020 Open Access This article is licensed under a Creative Commons Attribution 4.0 International License, which permits use, sharing, adaptation, distribution and reproduction in any medium or format, as long as you give appropriate credit to the original author(s) and the source, provide a link to the Creative Commons licence, and indicate if changes were made. The images or other third party material in this article are included in the article's Creative Commons licence, unless indicated otherwise in a credit line to the material. If material is not included in the article's Creative Commons licence and your intended use is not permitted by statutory regulation or exceeds the permitted use, you will need to obtain permission directly from the copyright holder. To view a copy of this licence, visit http://creativecommons.org/licenses/by/4.0/ The Creative Commons Public Domain Dedication waiver (http://creativecommons.org/publicdomain/zero/1.0/) applies to the data made available in this article, unless otherwise stated in a credit line to the data. 
LASIK and SMILE [4, 5]. Posterior corneal elevation (PCE) and anterior chamber depth (ACD) are also reduced [6,7], but few studies have investigated changes in the retina.

Optical coherence tomography angiography (OCTA) has predominated now-a-days for its deep scan and retinal vascular quantitative analysis. Previous studies have shown that retinal microvascularity decreases in myopia patients $[8,9]$. Prior studies have suggested that suction during surgery is a crucial factor responsible for all ocular changes $[10,11]$. In this study, we measured both the anterior and posterior parameter outcomes after SMILE.

\section{Methods}

\section{Participants}

This was a prospective observational study. The design and procedure of this study adhered to the principles of the Declaration of Helsinki. The Institutional Review Board of Ruijin Hospital authorised this study. Patients who were willing to undergo SMILE at Ruijin Hospital from August 2019 to December 2019 were enrolled. Written informed consent was obtained from each subject.

The inclusion criteria were as follows: age $>18$ years, corrected distance visual acuity no less than 20/20, without any ophthalmologic or systematic disease, stable myopia for more than two years, and calculated residual stromal bed $>250 \mu \mathrm{m}$.

\section{Measurement of clinical examination}

All participants underwent a complete ophthalmologic examination before and 1 day, 1 week after the surgery,

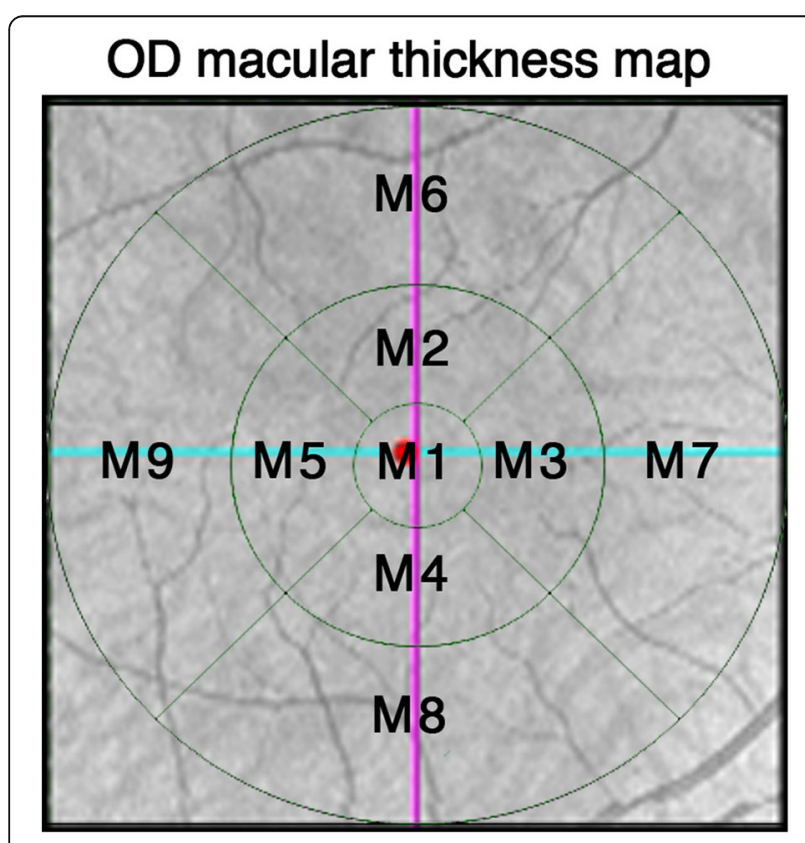

Fig. 1 Macular thickness map of the right eyes based on OCT

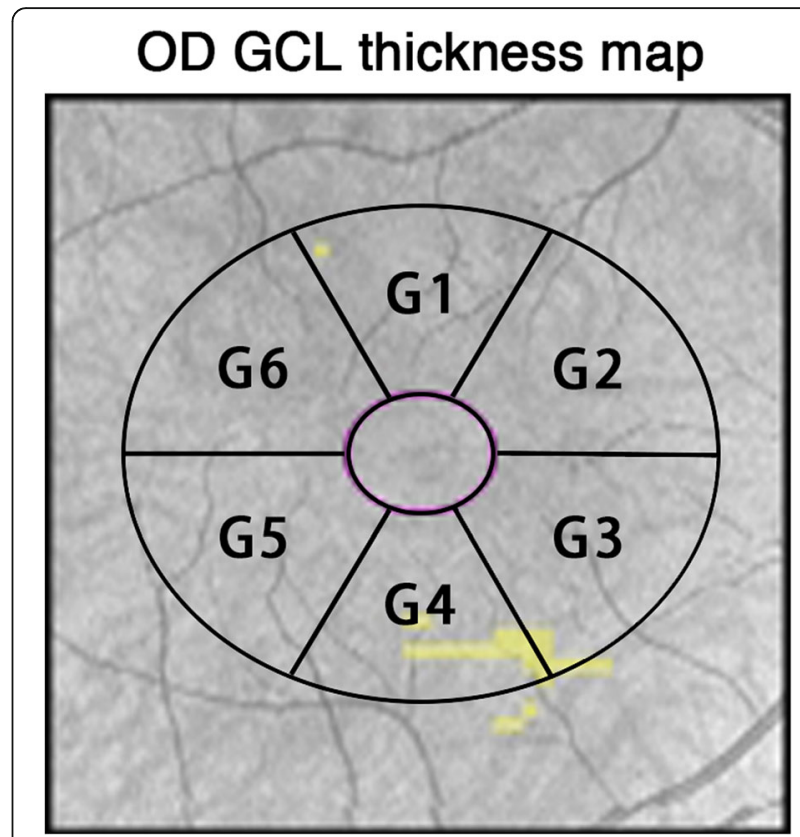

Fig. 2 Ganglion cell layer thickness map of the right eyes based on OCT

including visual acuity assessment, intraocular pressure (IOP), and refraction. Axial length (AL), central corneal thickness (CCT), anterior chamber depth (ACD), lens thickness (LT), white to white (WTW), and pupil diameter (PD) were measured using Lenstar (LS 900) and corneal tomography captured with Patencam (Oculus,

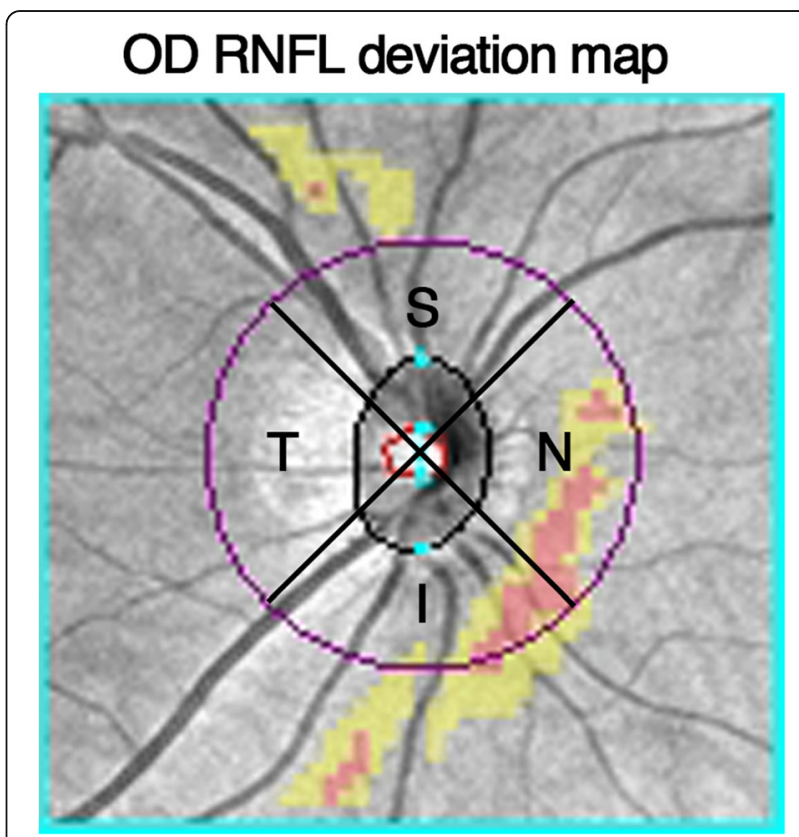

Fig. 3 Retinal nerve fiber layer deviation map of the right eyes based on OCT 


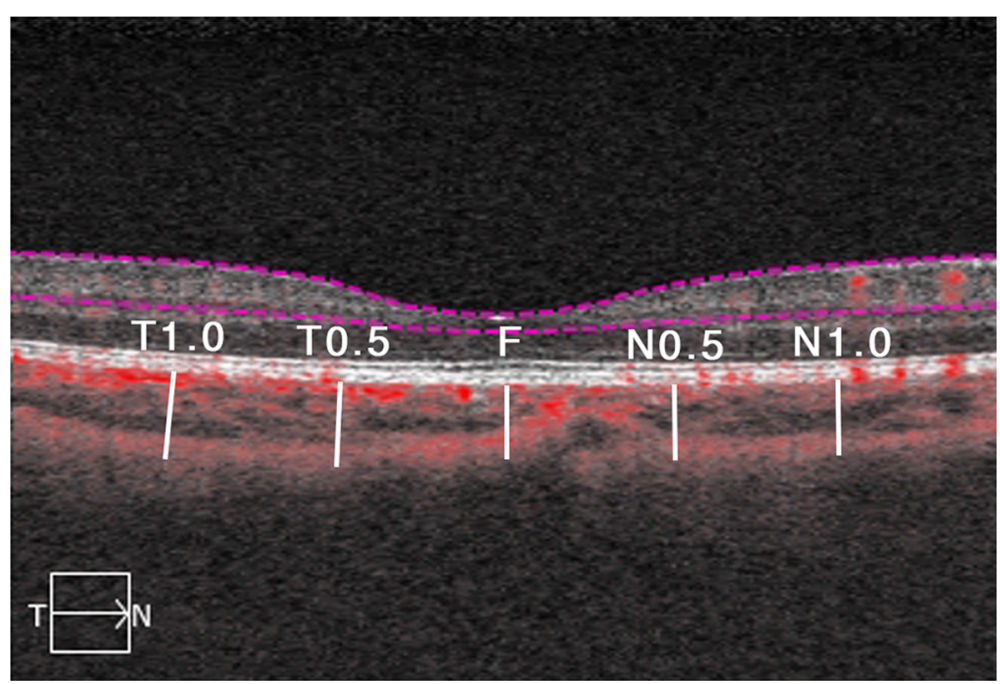

Fig. 4 Choroidal thickness measurement of the fovea (F), $0.5 \mathrm{~mm}$, and $1.0 \mathrm{~mm}$ from the fovea in nasal and temporal respectively (N0.5, N1.0, T0.5, T1.0)

Wetzlar, Germany). Changes of ACD and LT were recorded as $\triangle \mathrm{ACD}$ (ACD after surgery - ACD before surgery) and $\Delta \mathrm{LT}$ (LT after surgery - LT before surgery).

OCT scans were captured with Cirrus HD OCT 5000(Carl Zeiss Meditec) software version 9.5.2, and analysed with a software version of 10.0.0. Five types of protocols were used to obtain images. Macular thickness (MT) and ganglion cell layer thickness (GCL) were obtained with a Macular Cube $512 \times 128$. Retinal fiber layer thickness (RNFL) was obtained with Optic Disc Cube $200 \times 200$, and choroidal thickness (CT) was obtained with Angiography $3 \times 3 \mathrm{~mm}$ enhanced depth imaging (EDI) mode, and the superficial vascular density of the macular and optic disk was obtained with angiography $6 \times 6 \mathrm{~mm}$.

MT, GCL, and RNFL were calculated automatically by OCT and shown in a map image. An MT map of nine zones from the internal limiting membrane (ILM) to the retinal pigment epithelium (RPE) was automatically calculated and recorded as M1-M9 (Fovea as M1, inner circle from superior to temporal as M2 to M5, outer circle from superior to temporal as M6 to M9) (Fig. 1). The GCL map of the six zones was recorded as G1-G6 (Fig. 2); the RNFL map of four zones was recorded as superior, nasal, temporal, and inferior (Fig. 3). CT was manually measured in the horizontal direction. The
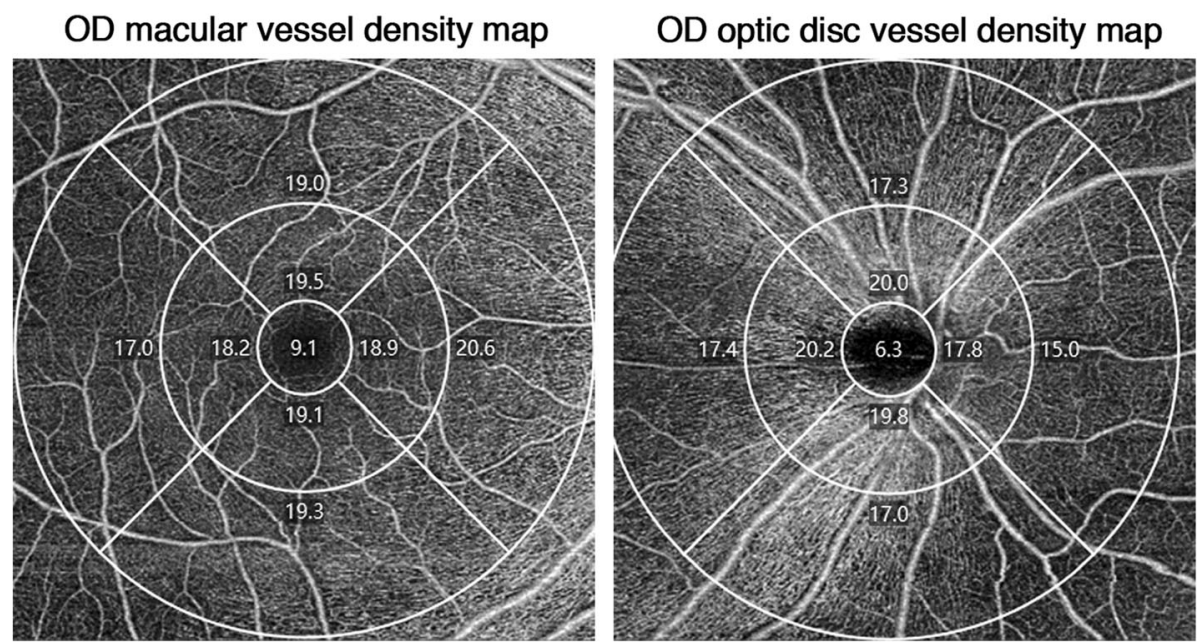

Fig. 5 Vessel density map of the macular and optic disc of the right eyes based on OCTA 
Table 1 Characteristics of the subjects

\begin{tabular}{ll}
\hline Parameters & \\
\hline Female/Male & $21 / 10$ \\
Age (years) & $27.81 \pm 7.09$ \\
sphere (D) & $-5.57 \pm 1.67$ \\
astigmatism (D) & $-0.62 \pm 0.36$ \\
ablation depth $(\mu \mathrm{m})$ & $115.95 \pm 24.42$ \\
\hline
\end{tabular}

boundary of the choroid was defined from the hyperreflective line of Bruch's membrane to the line of the inner surface of the sclera. Fovea and points $0.5 \mathrm{~mm}$, and $1.0 \mathrm{~mm}$ from the fovea in the nasal and temporal areas were measured (Fig. 4). Each point was measured three times for obtaining the mean value.

The vessel density map of the fovea and optic disk was a $6 \mathrm{~mm}$ diameter circle, divided into nine regions with three concentric circles. The inner one was $1.0 \mathrm{~mm}$ in diameter, middle one was $3 \mathrm{~mm}$, and outer one was 6 $\mathrm{mm}$. The circle was centred on the fovea and optic disc; the software automatically calculated values in each region of vessel density. Zones were recorded as A1-A9 and $\mathrm{O} 1-\mathrm{O} 9$, respectively, and the sequence was identical to the MT map (Fig. 5).

One skilled doctor obtained all the OCT scans. Images with signal strength higher than six were selected for analysis.

\section{Surgery process}

Surgeries were performed using a VisuMax (Carl Zeiss Meditec) femtosecond laser platform by one experienced surgeon. Before surgery, $0.5 \%$ proparacaine hydrochloride (Alcon-couvreur N. V, Belgium) was used for anaesthesia. The suction time was $23 \mathrm{~s}$ for lenticule creation. The angle of the lenticule side cut was $90^{\circ}$. The cap depth was $120 \mu \mathrm{m}$ with a diameter of $7.5 \mathrm{~mm}$ and a side cut angle of $120^{\circ}$. After the surgery, topical steroids (fluorometholone 0.1\%; Santen Pharmaceutical Co., Ltd.) was used 6 times a day and reduced every 5-7 days over 30 days. Topical antibiotics (ofloxacin ophthalmic solution 0.5\%; Santen Pharmaceutical Co., Ltd.) was used 4 times a day for 14 days. Artificial tears (sodium hyaluronate $0.1 \%$, Santen Pharmaceutical Co., Ltd.) was used 4 times a day for at least 1 month.

\section{Statistical analysis}

Statistical analysis was performed using SPSS 20.0 (IBM Corporation, Chicago, IL, USA). All values are expressed as mean \pm SD. Analysis of paired Student's t-test was used to assess the differences in CCT, ACD, LT, WTW, PD, MT, GCL, RNFL, CT, vessel density of macular and optic disk before and after surgery. Correlations between sphere and $\Delta \mathrm{ACD}$ and $\Delta \mathrm{LT}$ were analysed with the Pearson correlation coefficient. Results were considered statistically significant when $p<0.05$.

\section{Results}

This study enrolled 61 eyes of 31 patients, including 21 females and 10 males. The mean age was $28.13 \pm 5.84$ years, ranging from 19 to 44 years. The mean sphere, astigmatism, and ablation depth are shown in Table 1.

$\mathrm{AL}, \mathrm{CCT}, \mathrm{ACD}$, and PD decreased 1 day and 1 week after surgery. LT was thickened 1 day after surgery and became even thicker after 1 week. WTW did not change at either time point (Table 2).

$\Delta \mathrm{ACD}$ and $\Delta \mathrm{LT}$ were not significantly correlated 1 day after surgery. $\triangle \mathrm{ACD}$ was negatively correlated with $\Delta \mathrm{LT}$ and sphere 1 week after surgery $(\mathrm{r}=-0.867, p<0.000$; $\mathrm{r}=-0.398, p=0.002) . \Delta \mathrm{LT}$ was positively correlated with the sphere 1 week after surgery $(\mathrm{r}=0.256, p=$ 0.048) (Figs. 6, 7 and 8).

One day after surgery, M1, M2, M3, and M5 were significantly reduced. One week after surgery, M1 and M5 were still thinner than the baseline. Moreover, M8 was thicker than the baseline 1 week after surgery (Table 3).

There were no significant changes observed in the GCL (Table 4).

The RNFL was thicker in the inferior segment 1 week after surgery (Table 5).

CT was detected thicker in the fovea 1 day after surgery and N1.0 1 week after surgery (Table 6).

Macular vessel density decreased significantly 1 day after surgery, and most regions recovered after 1 week (Table 7).

Table 2 Ocular parameters measurement before and after surgery with Lenstar

\begin{tabular}{llllll}
\hline & before surgery & 1 day after surgery & p & 1 week after surgery & p \\
\hline AL $(\mathrm{mm})$ & $25.96 \pm 1.01$ & $25.86 \pm 0.99$ & $<0.000$ & $25.83 \pm 1.00$ & $<0.000$ \\
CCT $(\mu \mathrm{m})$ & $540.23 \pm 25.85$ & $446.97 \pm 30.48$ & $<0.000$ & $439.25 \pm 29.67$ & $<0.000$ \\
ACD $(\mu \mathrm{m})$ & $3.10 \pm 0.29$ & $3.04 \pm 0.29$ & $<0.000$ & $3.01 \pm 0.30$ & $<0.000$ \\
LT $(\mathrm{mm})$ & $3.69 \pm 0.33$ & $3.71 \pm 0.32$ & 0.032 & $3.76 \pm 0.33$ & $<0.000$ \\
WTW $(\mathrm{mm})$ & $11.95 \pm 0.46$ & $11.95 \pm 0.51$ & 0.955 & $11.95 \pm 0.48$ & 0.909 \\
PD $(\mathrm{mm})$ & $5.22 \pm 0.95$ & $4.56 \pm 0.80$ & $<0.000$ & $4.69 \pm 0.87$ & $<0.000$ \\
\hline
\end{tabular}

$A L$ axial length, $C C T$ central cornea thickness, $A C D$ anterior chamber depth, $L T$ lens thickness, WTW white to white, $P D$ pupil diameter 


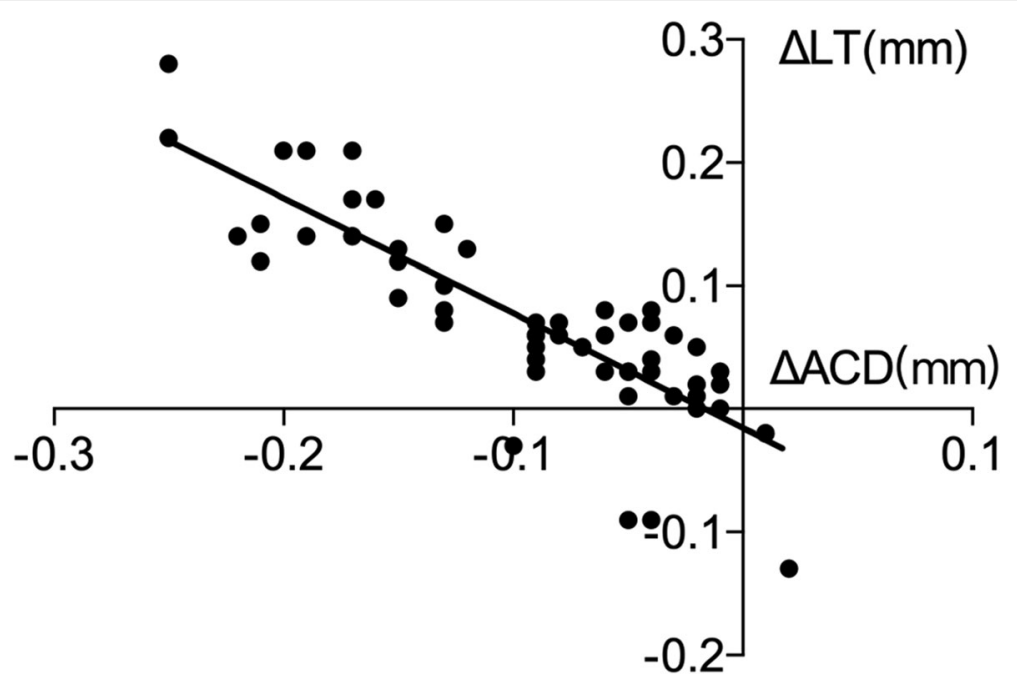

Fig. $\boldsymbol{6}$ Correlation between $\boldsymbol{\Delta A C D}$ and $\boldsymbol{\Delta} \mathrm{LT} 1$ week after surgery

Optic disc vessel density was reduced at the optic disc and peripapillary part (O5-O9) 1 day after surgery and recovered after 1 week (Table 8).

\section{Discussion}

In this study, we measured several parameters and found that both the anterior segment and retina were affected by the surgery. Results from previous studies suggested that anterior segment changes would last for a long time, while posterior segment changes are only observed for a short time and then gets resolved. Prior studies have reported that PCE and ACD decreased after surgery and even several years later [6,7], and this change was more significant in younger patients [12]. It has also been reported that changes in elevation correlated with residual bed thickness [13]. In this study, the $\triangle \mathrm{ACD}$ negatively correlated with sphere, this suggested that severe myopia was with more ablation depth and less residual bed thickness, leading to decreased cornea biomechanics and $\mathrm{ACD}$. Besides, a negative correlation between $\triangle \mathrm{ACD}$ and $\Delta \mathrm{LT}$ affirmed that thickened $\mathrm{LT}$ also attributed to the reduced $A C D$.

AL shortened by approximately $0.1 \mathrm{~mm}$ after surgery due to the ablation part. Corneas were usually oedematous after SMILE so that CCT was thinner 1 week than 1 day after surgery, and another article had the same result [14].

In a previous study regarding the treatment of presbyopia using a femtosecond laser, they found that the crystalline lens moved axially and laterally, and it seemed

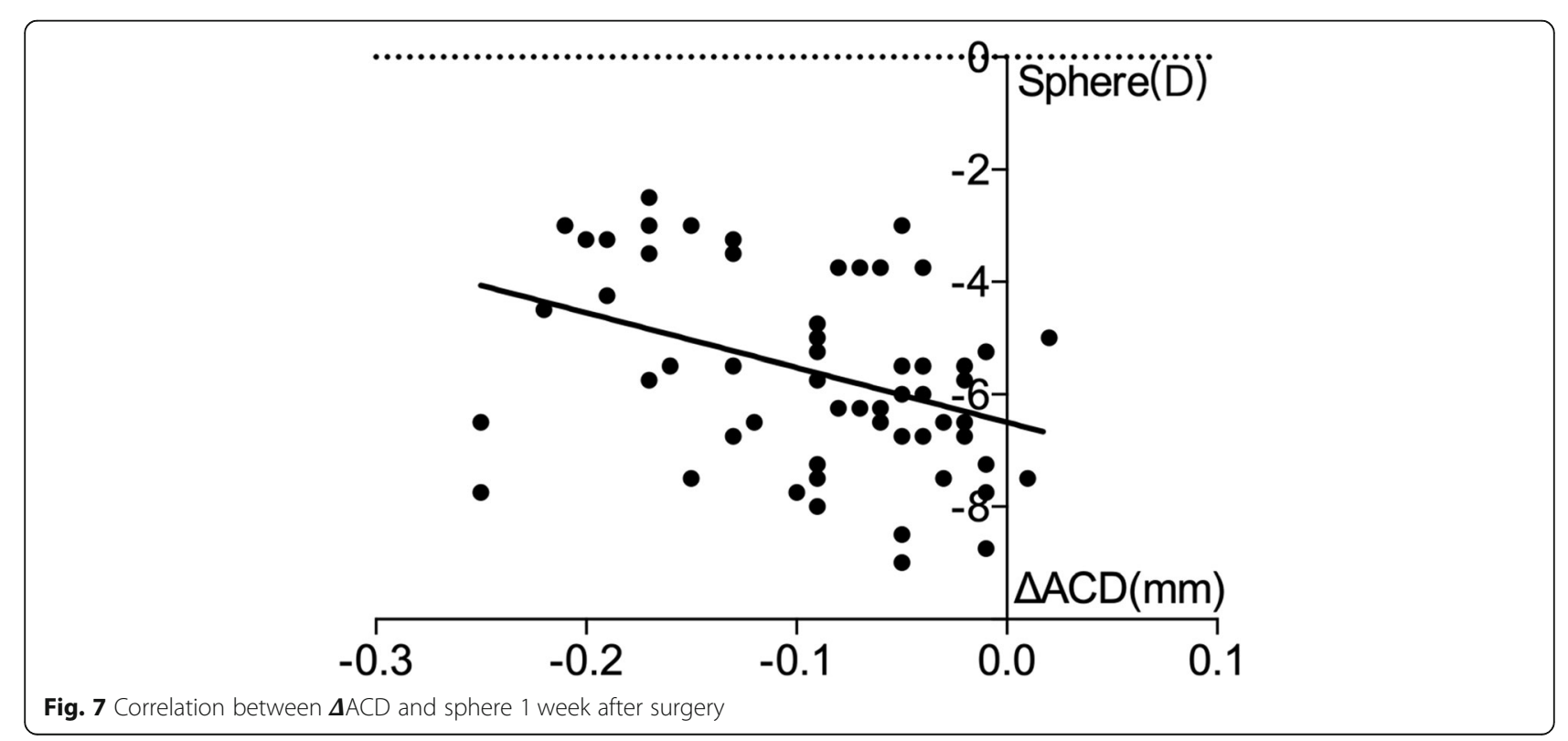




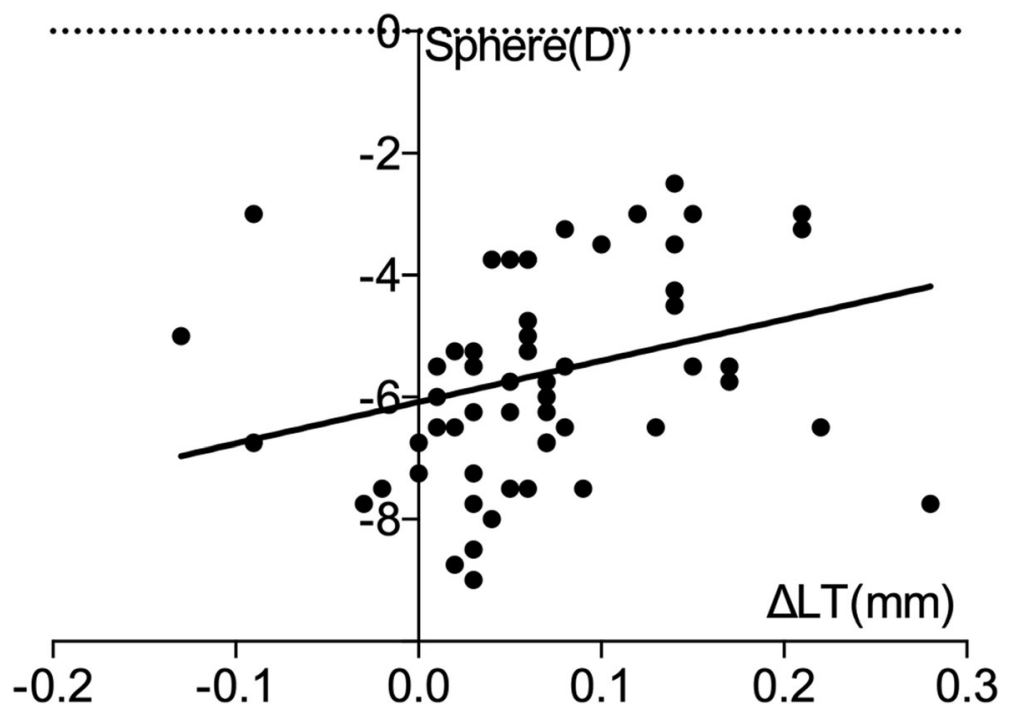

Fig. 8 Correlation between $\boldsymbol{\Delta L T}$ and sphere 1 week after surgery

to be affected by suction [10]. The effect of suction usually lasts for a brief time. Our results showed that LT thickened in 1 day and were even thicker 1 week, so suction may not be the predominant factor. Other researchers found that LT increased after LASIK with four different instruments, and the pupil was dilated with $0.5 \%$ tropicamide before each measurement. The authors believed that residual accommodation might contribute to the LT increase [15]. In our study, all patients had natural pupils and were accompanied with thicker LT, and smaller PD than preoperative. This may prove the hypothesis that accommodation is enhanced after refractive surgery. Another study found that the amplitude of accommodation (AA) significantly decreased postoperatively. In our study, a slightly positive correlation between $\Delta \mathrm{LT}$ and sphere suggested that severe myopia had less AA, which may explain that some patients complained of accommodation hysteresis after surgery, especially highly myopic patients. The poor accommodative ability, slow accommodative responsiveness, and increased accommodation demand may attribute to these results [16].

There are few articles reporting retinal or choroidal changes after SMILE, but changes after LASIK have been studied extensively. In previous LASIK studies, MT was thickened [11], or total macular volume increased [17]. 1 day after surgery, all parameters returned to baseline [18]. In our study, MT decreased after surgery, but GCL was unchanged, which was similar to prior study [19]. With the reduced M1, M2, M3, and M5, M8 increased in 1 week, which is contradictory to prior study findings on LASIK. The reason for decrease in MT and determination of the thinner layer require more indepth studies.

Twenty years ago, RNFL changes after LASIK attracted doctors' interests, and different results were concluded. RNFL was found to change with scanning laser polarimetry (SLP) but unchanged with OCT [20].

Table 3 Macular thickness ( $\mu \mathrm{m}$ ) before and after surgery with OCT

\begin{tabular}{llllll}
\hline & before surgery & $\mathbf{1}$ day after surgery & $\mathbf{p}$ & 1 week after surgery & $\mathbf{p}$ \\
\hline M1 & $248.88 \pm 20.18$ & $246.07 \pm 19.41$ & $<0.000$ & $246.26 \pm 20.41$ & $<0.000$ \\
M2 & $319.16 \pm 13.21$ & $316.31 \pm 16.17$ & 0.009 & $318.21 \pm 13.28$ & 0.119 \\
M3 & $319.36 \pm 14.68$ & $315.82 \pm 16.95$ & 0.003 & $317.80 \pm 14.34$ & 0.035 \\
M4 & $309.69 \pm 13.34$ & $307.95 \pm 13.88$ & 0.105 & $309.49 \pm 13.03$ & 0.812 \\
M5 & $303.62 \pm 11.68$ & $301.36 \pm 12.56$ & 0.001 & $302.49 \pm 11.84$ & 0.022 \\
M6 & $278.57 \pm 13.99$ & $276.80 \pm 12.94$ & 0.190 & $278.26 \pm 12.19$ & 0.761 \\
M7 & $294.72 \pm 13.13$ & $293.68 \pm 12.13$ & 0.276 & $293.80 \pm 13.15$ & 0.393 \\
M8 & $257.31 \pm 12.31$ & $258.31 \pm 11.43$ & 0.273 & $259.34 \pm 12.61$ & 0.022 \\
M9 & $254.64 \pm 11.43$ & $254.87 \pm 10.08$ & 0.740 & $255.34 \pm 10.54$ & 0.087 \\
\hline
\end{tabular}


Table 4 GCL thickness ( $\mu \mathrm{m})$ before and after surgery with OCT

\begin{tabular}{llllll}
\hline & before surgery & 1 day after surgery & p & 1 week after surgery & p \\
\hline G1 & $83.21 \pm 5.39$ & $82.83 \pm 5.13$ & 0.422 & $83.36 \pm 4.74$ & 0.696 \\
G2 & $83.57 \pm 4.74$ & $83.67 \pm 4.44$ & 0.835 & $83.81 \pm 4.43$ & 0.520 \\
G3 & $81.74 \pm 6.11$ & $81.72 \pm 4.41$ & 0.981 & $81.65 \pm 4.70$ & 0.859 \\
G4 & $77.69 \pm 5.43$ & $78.47 \pm 4.64$ & 0.069 & $78.43 \pm 5.80$ & 0.152 \\
G5 & $80.77 \pm 4.75$ & $81.21 \pm 4.35$ & 0.269 & $81.21 \pm 4.41$ & 0.077 \\
G6 & $82.64 \pm 6.30$ & $81.89 \pm 4.05$ & 0.288 & $82.13 \pm 4.07$ & 0.392 \\
\hline
\end{tabular}

Table 5 RNFL thickness $(\mu \mathrm{m})$ before and after surgery with OCT

\begin{tabular}{llllll}
\hline & before surgery & 1 day after surgery & $\mathbf{p}$ & 1 week after surgery & $\mathbf{p}$ \\
\hline superior & $118.58 \pm 17.42$ & $118.90 \pm 16.36$ & 0.768 & $120.17 \pm 15.56$ & 0.118 \\
nasal & $62.41 \pm 8.58$ & $61.85 \pm 7.43$ & 0.687 & $61.56 \pm 7.25$ & 0.373 \\
inferior & $115.19 \pm 12.38$ & $116.66 \pm 14.33$ & 0.322 & $118.36 \pm 14.15$ & $<0.000$ \\
temporal & $96.25 \pm 21.32$ & $95.80 \pm 20.85$ & 0.595 & $94.80 \pm 20.51$ & 0.267 \\
\hline
\end{tabular}

Table 6 Choroidal thickness $(\mu \mathrm{m})$ before and after surgery with OCT

\begin{tabular}{llllll}
\hline & before surgery & 1 day after surgery & p & 1 week after surgery & p \\
\hline F & $274.80 \pm 64.24$ & $282.05 \pm 65.28$ & 0.041 & $281.18 \pm 58.86$ & 0.138 \\
N0.5 & $254.57 \pm 58.58$ & $257.20 \pm 62.80$ & 0.360 & $258.74 \pm 53.68$ & 0.304 \\
T0.5 & $262.34 \pm 58.58$ & $266.54 \pm 51.79$ & 0.143 & $271.65 \pm 54.50$ & 0.068 \\
N1.0 & $239.34 \pm 56.37$ & $243.31 \pm 57.48$ & 0.147 & $249.15 \pm 55.86$ & 0.029 \\
T1.0 & $266.32 \pm 54.14$ & $268.36 \pm 49.17$ & 0.365 & $268.13 \pm 51.62$ & 0.686 \\
\hline
\end{tabular}

Table 7 Macular vessel density $\left(\mathrm{mm}^{-1}\right)$ before and after surgery with OCTA

\begin{tabular}{llllll}
\hline & before surgery & 1 day after surgery & p & 1 week after surgery & p \\
\hline A1 & $7.94 \pm 3.02$ & $5.00 \pm 2.43$ & $<0.000$ & $6.91 \pm 2.53$ & 0.003 \\
A2 & $17.35 \pm 2.06$ & $14.17 \pm 3.26$ & $<0.000$ & $16.70 \pm 1.88$ & 0.055 \\
A3 & $17.13 \pm 2.23$ & $14.48 \pm 2.95$ & $<0.000$ & $16.58 \pm 2.09$ & 0.118 \\
A4 & $16.69 \pm 2.43$ & $13.97 \pm 3.20$ & $<0.000$ & $16.09 \pm 2.45$ & 0.112 \\
A5 & $16.31 \pm 2.66$ & $13.47 \pm 3.22$ & $<0.000$ & $15.59 \pm 2.32$ & 0.047 \\
A6 & $17.84 \pm 1.59$ & $15.92 \pm 2.20$ & $<0.000$ & $17.19 \pm 1.57$ & 0.012 \\
A7 & $19.71 \pm 1.20$ & $18.44 \pm 1.87$ & $<0.000$ & $19.12 \pm 2.25$ & 0.053 \\
A8 & $17.26 \pm 2.11$ & $15.06 \pm 2.79$ & $<0.000$ & $16.79 \pm 1.93$ & 0.140 \\
A9 & $14.96 \pm 3.06$ & $13.17 \pm 2.63$ & $<0.000$ & $14.64 \pm 2.33$ & 0.463 \\
\hline
\end{tabular}


Table 8 Optic disc vessel density $\left(\mathrm{mm}^{-1}\right)$ before and after surgery with OCTA

\begin{tabular}{llllll}
\hline & before surgery & 1 day after surgery & $\mathbf{p}$ & 1 week after surgery & $\mathbf{p}$ \\
\hline O1 & $6.63 \pm 5.20$ & $5.91 \pm 4.75$ & 0.001 & $6.38 \pm 4.71$ & 0.425 \\
O2 & $19.14 \pm 1.86$ & $18.98 \pm 1.99$ & 0.550 & $19.35 \pm 0.79$ & 0.389 \\
O3 & $17.90 \pm 2.73$ & $17.20 \pm 3.63$ & 0.047 & $18.08 \pm 2.04$ & 0.561 \\
O4 & $18.95 \pm 1.43$ & $18.45 \pm 2.54$ & 0.099 & $18.93 \pm 1.56$ & 0.923 \\
O5 & $18.36 \pm 2.98$ & $17.67 \pm 3.35$ & 0.014 & $17.83 \pm 3.40$ & 0.187 \\
O6 & $17.84 \pm 2.70$ & $16.39 \pm 3.20$ & $<0.000$ & $17.60 \pm 1.94$ & 0.417 \\
O7 & $15.19 \pm 3.31$ & $12.97 \pm 3.72$ & $<0.000$ & $14.49 \pm 2.68$ & 0.121 \\
O8 & $17.26 \pm 2.88$ & $15.69 \pm 3.27$ & 0.001 & $16.97 \pm 2.46$ & 0.400 \\
O9 & $17.77 \pm 3.03$ & $15.93 \pm 3.75$ & 0.001 & $17.45 \pm 2.78$ & 0.439 \\
\hline
\end{tabular}

This result was caused by corneal birefringence [21], but not the real RNFL changes. Other researchers believed that the RNFL did reduce, but only for a very short time after surgery and soon recovers. Suction during surgery and high IOP caused disorders of the optic nerve axoplasm and malnutrition of retinal ganglia cells [11]. Nevertheless, research in children revealed that MT was thicker 1 day after surgery, but RNFL remained unchanged [22]. Another study found that the RNFL was thicker 3 months after LASIK, especially in the inferiortemporal sector [23], which was similar to our results, but the possible mechanism is still not clear.

CT was observed thickened postoperatively [16], and there is research believing that $\mathrm{CT}$ was affected by ciliary muscle contraction, which may explain why LT thickened. In our study, the results were similar, but not every measure point was statistically significant.

Vessel density has been studied extensively in glaucoma and retinal diseases since OCTA emerged. Vessel density changes were assumed by the suction effects during surgery on the retinal microcirculation, and instantaneous changes in suction may cause ischaemiareperfusion injury [11]. IOP elevation during surgery also caused a decrease in ocular blood flow [24]. In a study on healthy people by increasing IOP, researchers found that transient elevation of IOP altered optic nerve head topography [25]. Other articles reported different results in a condition of natural IOP elevation and found no meaningful clinical impact [26]. In this study, macular vessel density and peripapillary vessel density were reduced. The recovery of macular vessel density was lower than peripapillary. Different retinal structures and sensitivity may be attributed for this effect. Reduced superficial vessel density also diminished vessel infusion, which may lead to thinner MT. Besides changes in the retina itself, the optical media may also affect OCT scanning due to mild corneal oedema postoperatively. The signal strength of images captured postoperatively was generally lower than that before surgery. This may be one reason for the reduced vessel density.
During the observation period, none of the patients had severe complications, and all of them regained ideal visual acuity. However, 1 day after the surgery, some corneas were not as clear as preoperatively due to mild corneal oedema, and it was difficult to capture high-quality images of the retina. Due to the limitation of the OCTA soft version, only superficial vessel density was analysed. These were the shortcomings of the study, along with the requirement of a longer follow-up period.

\section{Conclusion}

After SMILE, the anterior segment was the most affected, while the retina also underwent changes with regard to MT, macular vessel density, and peripapillary vessel density. This study can help doctors gain deep insights into changes after refractive surgeries.

\section{Abbreviations}

PRK: Photorefractive keratectomy; LASIK: Laser in situ keratomileusis; LASEK: laser subepithelial keratomileusis; SMILE: Small incision lenticule extraction; PCE: Posterior corneal elevation; OCTA: Optical coherence tomography angiography; IOP: Intraocular pressure; AL: Axial length; CCT: Central corneal thickness; ACD: Anterior chamber depth; LT: Lens thickness; WTW: White to white; PD: Pupil diameter; MT: Macular thickness; GCL: Ganglion cell layer; RNFL: Retinal nerve fiber layer; CT: Choroidal thickness; EDI: Enhanced depth imaging

\section{Acknowledgments \\ Not applicable.}

\section{Authors' contributions}

All authors conceived and designed the protocol. HL and YS recruited patients and provided follow up treatment for the patients. YC collected and analyzed the data and wrote the manuscript. XS performed a critical revision of the manuscript for intellectual content. All authors have read and approved the final manuscript.

\section{Funding}

None.

Availability of data and materials

All the relevant data of this study are available from the corresponding author upon request.

Ethics approval and consent to participate

The design and procedure of this research adhered to the principles of the Declaration of Helsinki. The Institutional Review Board of Ruijin Hospital 
authorized this study. Written informed consent was obtained from each subject.

\section{Consent for publication}

Not applicable.

\section{Competing interests}

The authors declare that they have no competing interests.

Received: 31 March 2020 Accepted: 30 September 2020

Published online: 07 October 2020

\section{References}

1. Trokel SL, Srinivasan R, Braren B. Excimer laser surgery of the cornea. Am J Ophthalmol. 1983;96(6):710-5.

2. Vestergaard A, Ivarsen AR, Asp S, Hjortdal JO. Small-incision lenticule extraction for moderate to high myopia: predictability, safety, and patient satisfaction. J Cataract Refract Surg. 2012;38(11):2003-10.

3. Blum M, Lauer AS, Kunert KS, Sekundo W. 10-Year Results of Small Incision Lenticule Extraction. J Refract Surg. 2019;35(10):618-23.

4. Wang D, Liu M, Chen Y, Zhang X, Xu Y, Wang J, CH T, Liu Q. Differences in the corneal biomechanical changes after SMILE and LASIK. J Refract Surg. 2014;30(10):702-7.

5. Chen M, Yu M, Dai J. Comparison of biomechanical effects of small incision lenticule extraction and laser-assisted subepithelial keratomileusis. Acta Ophthalmol. 2016;94(7):e586-91.

6. Yu M, Chen M, Dai J. Comparison of the posterior corneal elevation and biomechanics after SMILE and LASEK for myopia: a short- and long-term observation. Graefe's Arch Clin Exp Ophthalmol. 2019;257(3):601-6.

7. Zhao Y, Jian W, Chen Y, Knorz MC, Zhou X. Three-Year Stability of Posterior Corneal Elevation After Small Incision Lenticule Extraction (SMILE) for Moderate and High Myopia. J Refract Surg. 2017;33(2):84-8.

8. Al-Sheikh M, Phasukkijwatana N, Dolz-Marco R, Rahimi M, lafe NA, Freund KB, Sadda SR, Sarraf D. Quantitative OCT angiography of the retinal microvasculature and the Choriocapillaris in myopic eyes. Invest Ophthalmol Vis Sci. 2017;58(4):2063-9.

9. Li M, Yang Y, Jiang H, Gregori G, Roisman L, Zheng F, Ke B, Qu D, Wang J. Retinal microvascular network and microcirculation assessments in high myopia. Am J Ophthalmol. 2017;174:56-67.

10. Kunert KS, Blum M, Reich M, Dick M, Russmann C. Effect of a suction device for femtosecond laser on anterior chamber depth and crystalline lens position measured by OCT. J Refract Surg. 2009;25(11):1005-11.

11. Zhang J, Zhou YH. Effect of suction on macular thickness and retinal nerve fiber layer thickness during LASIK used femtosecond laser and Moria M2 microkeratome. Int J Ophthalmol. 2015:8(4):777-83.

12. Nishimura R, Negishi K, Dogru M, Saiki M, Arai H, Toda I, Yamaguchi T, Tsubota K. Effect of age on changes in anterior chamber depth and volume after laser in situ keratomileusis. J Cataract Refract Surg. 2009;35(11):1868-72.

13. Zhou X, Shang J, Qin B, Zhao Y, Zhou X. Two-year observation of posterior corneal elevations after small incision lenticule extraction (SMILE)for myopia higher than -10 dioptres. Br J Ophthalmol. 2020;104(1):142-8.

14. Liu T, Dan T, Luo Y. Small incision Lenticule extraction for correction of myopia and myopic astigmatism: first 24-hour outcomes. J Ophthalmol. 2017:2017:5824534.

15. Wang L, Guo HK, Zeng J, Jin HY. Analysis of changes in crystalline lens thickness and its refractive power after laser in situ keratomileusis. Int J Ophthalmol. 2012;5(1):97-101.

16. Li M, Cheng H, Yuan Y, Wang J, Chen Q, Me R, Ke B. Change in choroidal thickness and the relationship with accommodation following myopic excimer laser surgery. Eye (Lond). 2016;30(7):972-8.

17. Feng L, Burns SA, Shao L, Yang Y. Retinal measurements using time domain OCT imaging before and after myopic Lasik. Ophthalmic Physiol Opt. 2012 ; 32(3):222-7.

18. Zhang J, Zhou Y, Zheng Y, Liu Q, Zhai C, Wang Y. Effect of suction on macular and retinal nerve fiber layer thickness during femtosecond lenticule extraction and femtosecond laser-assisted laser in situ keratomileusis. J Cataract Refract Surg. 2014;40(12):1994-2001.

19. Zivkovic M, Jaksic V, Giarmoukakis A, Grentzelos M, Zlatanovic M, Zlatanovic G, Miljkovic A, Jovanovic S, Stamenkovic M, Kymionis G. The effect of LASIK procedure on Peripapillary retinal nerve Fiber layer and macular ganglion cell-inner Plexiform layer thickness in myopic eyes. Biomed Res Int. 2017; 2017:8923819.

20. Gurses-Ozden R, Liebmann JM, Schuffner D, Buxton DF, Soloway BD, Ritch $R$. Retinal nerve fiber layer thickness remains unchanged following laserassisted in situ keratomileusis. Am J Ophthalmol. 2001;132(4):512-6.

21. Choplin NT, Schallhorn SC, Sinai M, Tanzer D, Tidwell JL, Zhou Q. Retinal nerve fiber layer measurements do not change after LASIK for high myopia as measured by scanning laser polarimetry with custom compensation. Ophthalmology. 2005;112(1):92-7.

22. Zhao PF, Zhou YH, Zhang J, Wei WB. Analysis of macular and retinal nerve Fiber layer thickness in children with refractory amblyopia after femtosecond laser-assisted laser in situ Keratomileusis: a retrospective study. Chin Med J. 2017;130(18):2234-40.

23. Katsanos A, Arranz-Marquez E, Canones R, Lauzirika G, Rodriguez-Perez I, Teus MA. Retinal nerve fiber layer thickness after laser-assisted subepithelial keratomileusis and femtosecond LASIK: a prospective observational cohort study. Clin Ophthalmol. 2018;12:1213-8.

24. Chen M, Dai J, Gong L. Changes in retinal vasculature and thickness after small incision Lenticule extraction with optical coherence tomography angiography. J Ophthalmol. 2019;2019:3693140.

25. Piette S, Liebmann JM, Ishikawa H, Gurses-Ozden R, Buxton D, Ritch R. Acute conformational changes in the optic nerve head with rapid intraocular pressure elevation: implications for LASIK surgery. Ophthalmic Surg Lasers Imaging. 2003;34(4):334-41.

26. Zhang Q, Jonas JB, Wang Q, Chan SY, Xu L, Wei WB, Wang YX. Optical coherence tomography angiography vessel density changes after acute intraocular pressure elevation. Sci Rep. 2018;8(1):6024.

\section{Publisher's Note}

Springer Nature remains neutral with regard to jurisdictional claims in published maps and institutional affiliations.

\section{Ready to submit your research? Choose BMC and benefit from:}

- fast, convenient online submission

- thorough peer review by experienced researchers in your field

- rapid publication on acceptance

- support for research data, including large and complex data types

- gold Open Access which fosters wider collaboration and increased citations

- maximum visibility for your research: over $100 \mathrm{M}$ website views per year

At BMC, research is always in progress.

Learn more biomedcentral.com/submissions 